\title{
Thoraco-omphalopagus Conjoined Twins: A Rare Case Report
}

\author{
Sarita Kumari ${ }^{1}$, Vipasha Singh ${ }^{2}$, Hemant K Mishra ${ }^{3}$
}

\begin{abstract}
Conjoined twins is a rare congenital malformation. It is a rare type of monozygotic monoamniotic monochorionic twins. Ultrasound is the standard investigation for fetal scanning. Here we present a case of conjoined twins diagnosed by transabdominal ultrasound examination at 23 weeks and 1 day gestation in a young female with a history of primary infertility and ovulation induction. They were joined at the chest and the abdomen and had one functional heart and one liver. The pregnancy was terminated by cesarean section at 23 weeks' gestation, with the approval of the family.

Keywords: Conjoined twins, Monozygotic monoamniotic monochorionic, Thoraco-omphalopagus twins.

Journal of Mahatma Gandhi University of Medical Sciences \& Technology (2018): 10.5005/jp-journals-10057-0087
\end{abstract}

\section{INTRODUCTION}

Conjoined twins also known as Siamese twins is a rare congenital human malformation. It is a rare type of monozygotic monoamniotic monochorionic twins. The first diagnosed case of conjoined twins was born in Siam in 1811 and hence the name Siamese twins. Both were males and lived for about 62 years. The incidence is very rare and reported to be between 1:33,000 to 1:165,000 pregnancies with 3:1 female predominance. ${ }^{1}$ Conjoined twins are not associated with maternal age or parity and has no genetic predisposition. It is due to incomplete splitting of monozygotic twins after 12 days of embryogenesis. On ultrasound, diagnosis can be suspected as early as 7 weeks of gestation. ${ }^{2}$ Morbidity and mortality are high with conjoined twins, hence antenatal diagnosis is important. All monozygotic twins should be screened for a possibility of conjointment. The common types of conjoined twins are thoracopagus and omphalopagus.

\section{Materials and Methods}

A 28-year-old female with a history of primary infertility with ovulation induction was referred to our department for anomaly scan at 23 weeks' and 1 day of gestation by last menstrual period (LMP). done.

Following this a real-time B-mode ultrasonography (USG) was The equipment used are the following:

- Voluson S6 (GE) ultrasound machine with 3D probe.

- X-ray. Machine 300 MA Allengers machine.

\section{Case Description}

A 28-year-old female with a history of primary infertility with ovulation induction had come for antenatal anomaly ultrasound scan at the radiology department of our hospital at 23 weeks' 1 day of gestation. Transabdominal scan showed monoamnioticmonochromic conjoined twins joined at the chest and the abdomen (thoraco-omphalopagus) with two separate spines, stomach bubbles, urinary bladders, a single liver (Figs 1 and 2), and a single functional heart (Figs 3 and 4) with fused unilateral upper and lower limbs (Figs 5 and 6). Single-limb deformities were noted in fetus B.
${ }^{1-3}$ Department of Radiodiagnosis, Mahatma Gandhi Medical College and Hospital, Mahatma Gandhi University of Medical Sciences and Technology, Jaipur, Rajasthan, India

Corresponding Author: Sarita Kumari, Department of Radiodiagnosis, Mahatma Gandhi Medical College and Hospital, Mahatma Gandhi University of Medical Sciences and Technology, Jaipur, Rajasthan, India, Phone: +91 9950791794, e-mail: saritajakhar1987@gmail.com

How to cite this article: Kumari S, Singh V, Mishra HK. Thoracoomphalopagus Conjoined Twins: A Rare Case Report. J Mahatma Gandhi Univ Med Sci Tech 2018;3(3):102-104.

Source of support: Nil

Conflict of interest: None

Both the fetal heads were found to be at the same level. Gestational age of the fetuses were 22 weeks 1 day (by USG) (Figs 7 and 8). After proper counseling, lower segment cesarean section was conducted on the patient at 23 weeks of gestation (Fig. 9). Gross examination (Fig. 10) of the fetus confirmed the diagnosis of thoraco-omphalopagus conjoined twins.

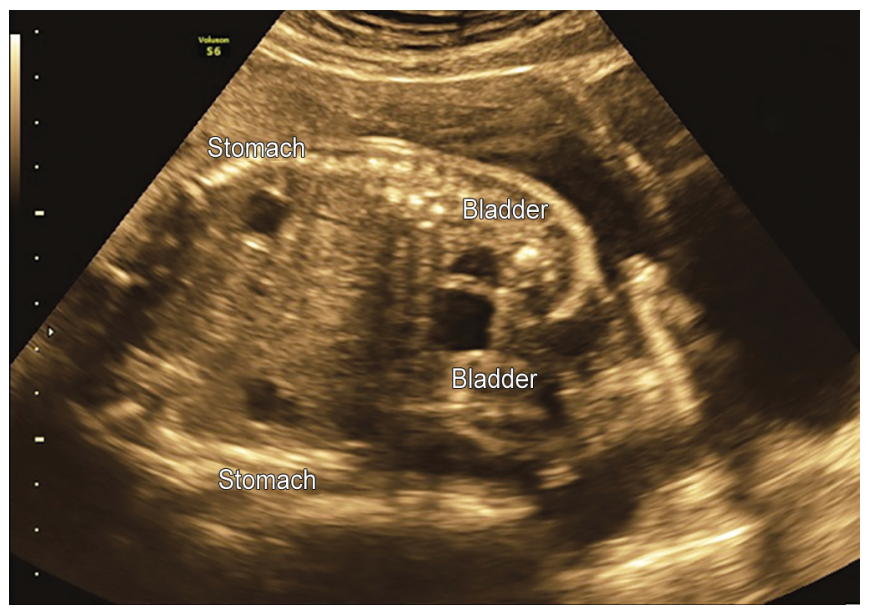

Fig. 1: Transabdominal ultrasound image showing two separate spine, stomach bubbles, urinary bladders and single liver 


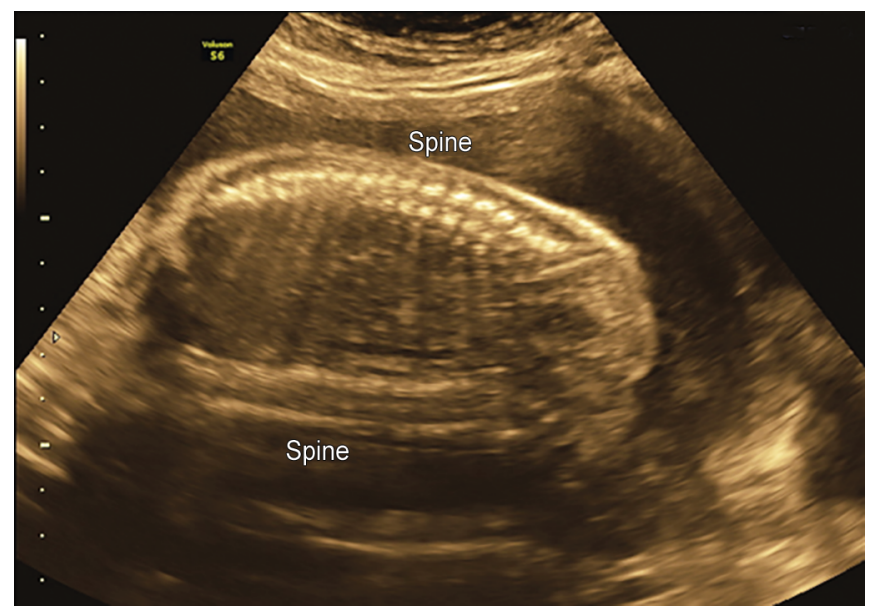

Fig. 2: Ultrasound showing two separate spines and single liver

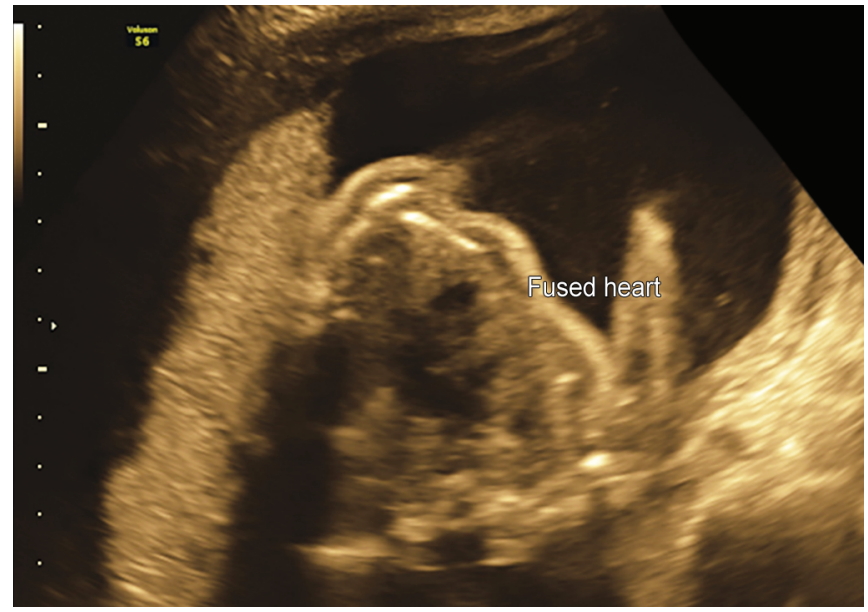

Fig. 4: Transabdominal ultrasound image of fusion site with single central heart

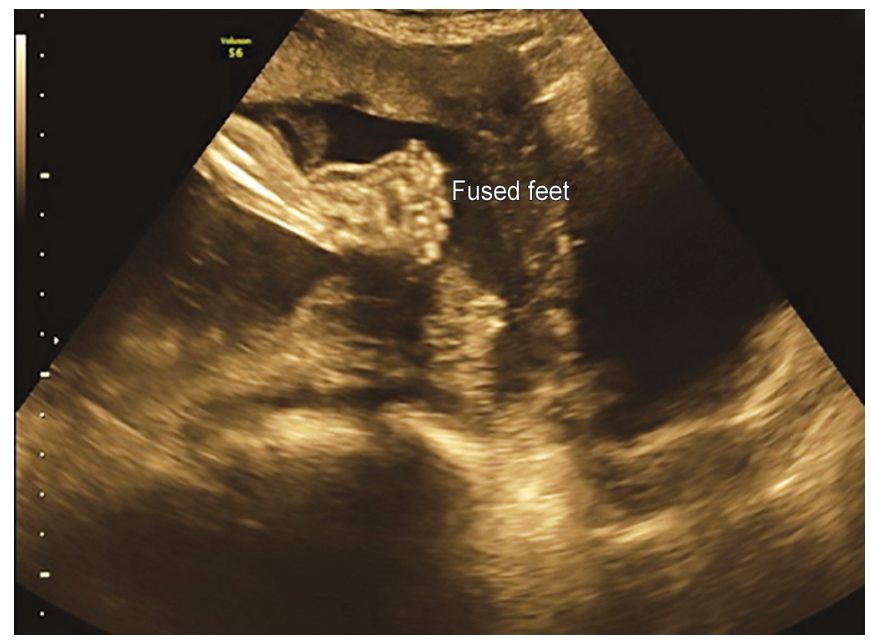

Fig. 6: Transabdominal ultrasound image showing fused unilateral feet

\section{Discussion}

The conjoined twins occur due to failure of normal and complete separation of the embryonic plate from incomplete delayed

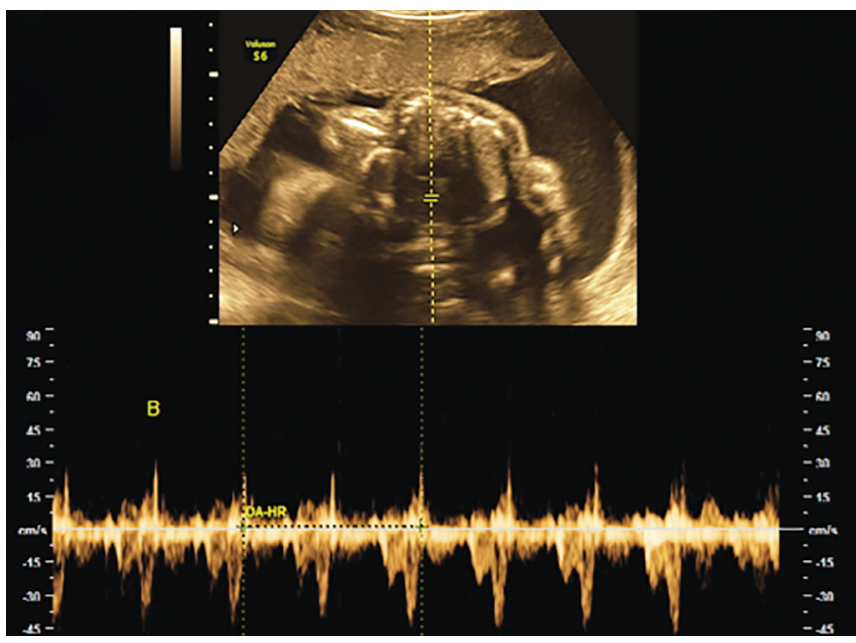

Fig. 3:Transabdominal ultrasound image of fusion site with single central heart with cardiac activity
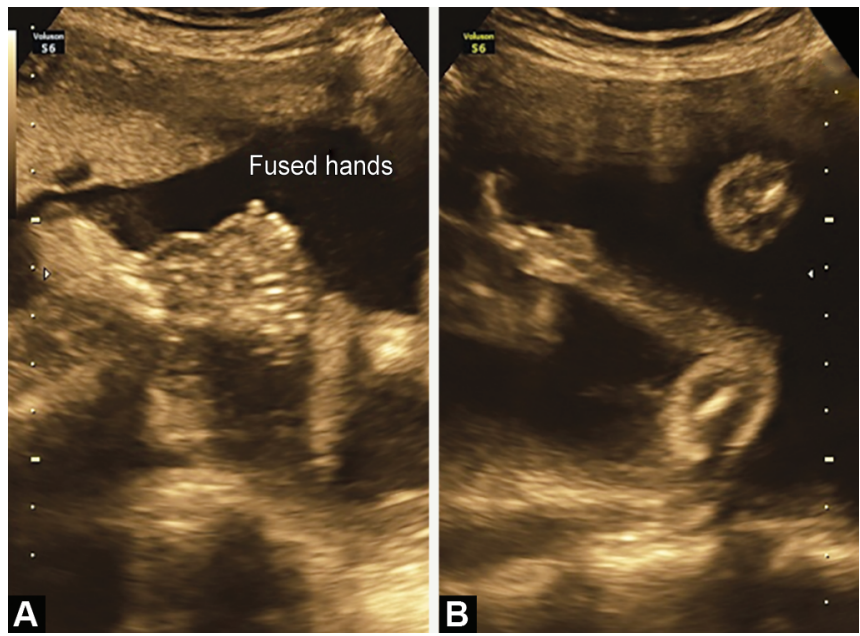

Figs $5 \mathrm{~A}$ and $\mathrm{B}$ : Transabdominal ultrasound image showing fused unilateral hands

division of the inner cell mass. This is thought to occur around 13-17 days of gestation. Conjoined twins and nonconjoined monozygotic twins share a single common chorion, amniotic sac, and placenta. Similar to all monozygotic twins, all conjoined twins also have the same sex.

Various types of conjoined twins are as follows: thoracoomphalopagus (chest, abdomen, or both), thoracopagus (joined at thorax), omphalopagus (joined at the anterior abdominal wall), craniopagus (joined at the cranium), syncephalus (joined twins with one head), and ischiopagus (joined at the buttocks); and among these, the most common ones are thoracopagus, omphalopagus, and thoraco-omphalopagus, which constitute almost $70 \%$ of conjoined twins. Conjoint twins have female predominance of 3:1 ratio. ${ }^{3,4}$ The risk factors include intake of clomiphene citrate and valproate during periconceptual period. No mutations are identified to be associated with conjoint twins. The overall survival rates depend upon the type of union and range between $20 \%$ and $25 \%$. There is no evidence of increased recurrence risk in case of pregnancy complicated by conjoined twins. In craniothoracopagus conjoined twins, prognosis is poor as there is only one brain and 

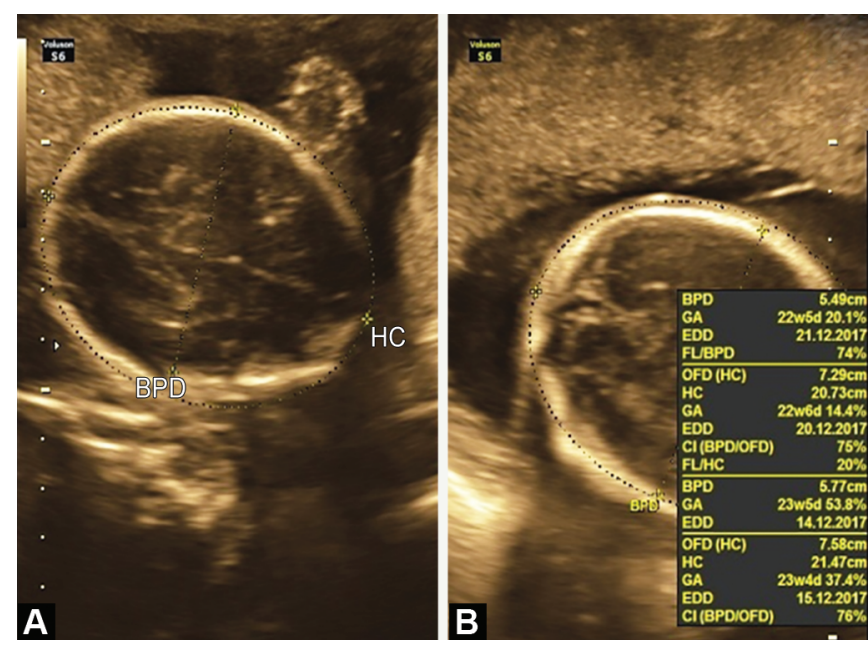

Figs 7A and B:Transabdominal ultrasound image of the conjoined twins with separate heads

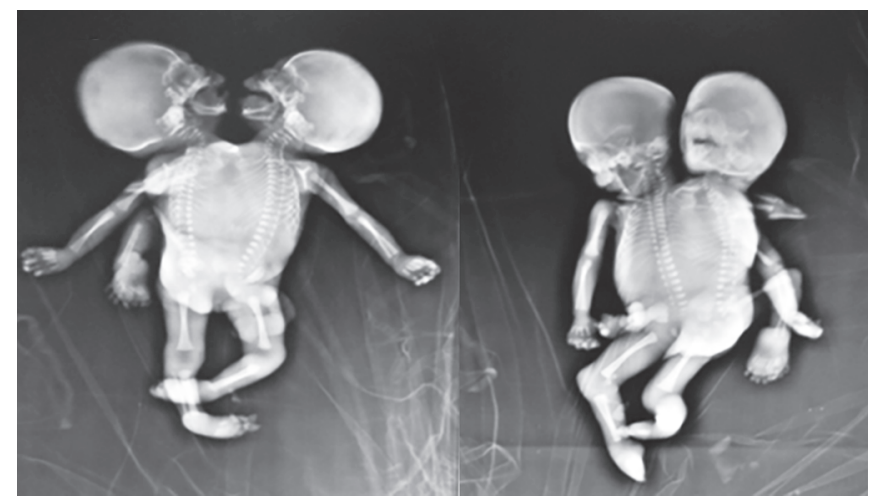

Fig. 9: Skiagram of the conjoined twins

surgical separation is not an available option, but fortunately this type of conjoint twins are rare. Craniopagus twins may be partial or complete depending upon whether they significantly share dural venous sinus system. The thoraco-omphalopagus types of conjoined twins may undergo complex surgery for separation if they are not sharing vital organs. On ultrasound, diagnosis can be suspected as early as 7 weeks of gestation. Transvaginal scan provides a better view, and the inability to separately see different parts of the fetuses may help in early diagnosis as compared to transabdominal scan.

\section{Conclusion}

A conjoined twin is a well-known rare entity. It is very important to make a diagnosis by ultrasound in time to prevent complications, so as to provide parents with an option for safe medical termination of pregnancy. Detailed anomaly scan at 18-20 weeks helps determine the shared organs and to detect the malformations. ${ }^{5}$
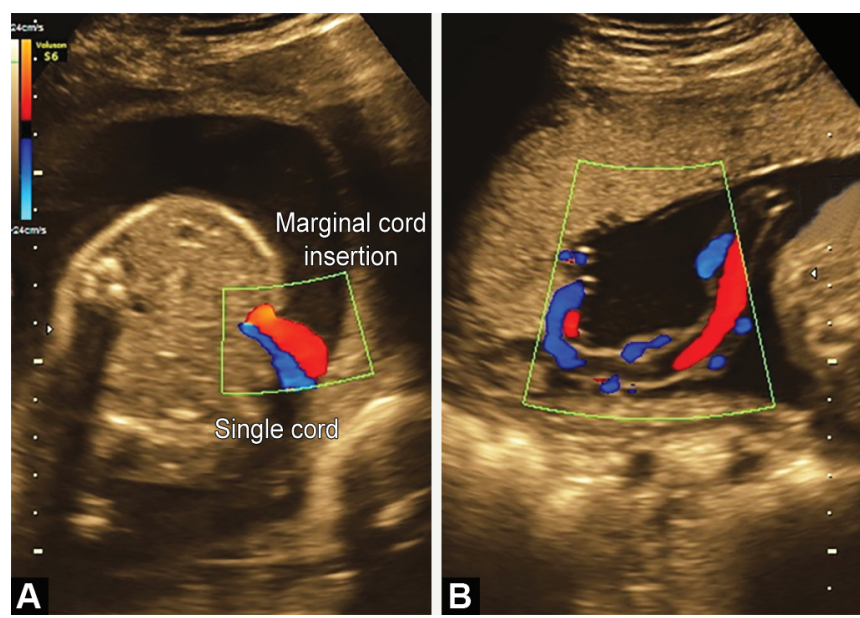

Figs $8 \mathrm{~A}$ and B:Transabdominal color Doppler ultrasound image of single fundoanterior placenta

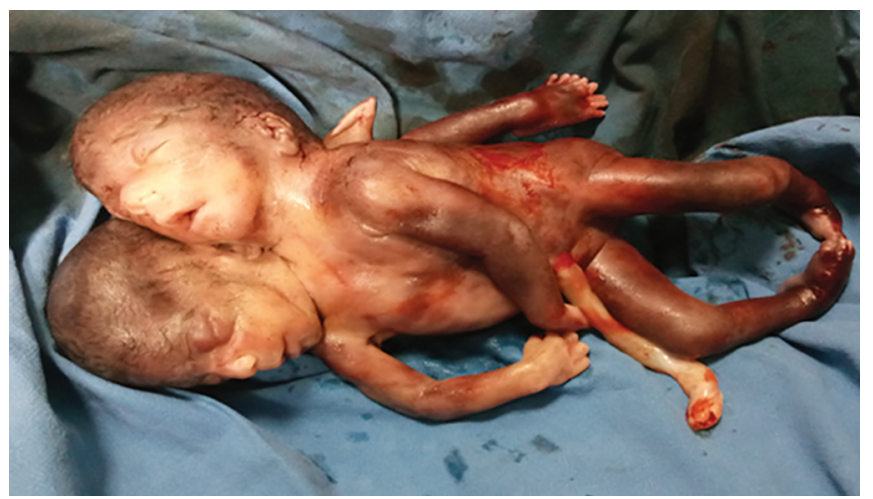

Fig. 10: Image immediately after delivery showing the thoracoomphalopagus conjoined twins

Thoraco-omphalopagus type is known to present several cardiac anomalies, i.e., a shared single four-chambered heart. ${ }^{6}$

\section{References}

1. Martin JA, Hamilton BE, Sutton PD, et al. Births: final data for 2005 . Natl Vital Stat Rep 2007;56(6):1-103.

2. Kaufman MH. The embryology of conjoined twins. Childs Nerv Syst 2004;20(8-9):508-525. DOI: 10.1007/s00381-004-0985-4.

3. Leachman RD, Latson JR, Kohler CM, et al. Cardiovascular evaluation of conjoined twins. Birthdefect 1967;3:52-65.

4. Seo JW, Lee YS, Chi JG. Cross-sectional illustration on major types of conjoined twins. J Korean Med Sci 1988;3(1):19-25. DOI: 10.3346/ jkms.1988.3.1.19.

5. Barth RA, Filly RA, Goldberg JD, et al. Conjoined twins: prenatal diagnosis and assessment of associated malformation. Radiology 1990;177(1):201-207. DOI: 10.1148/radiology.177.1.2204966.

6. Tannuri ACA, Batatinha JAP, Velhote MCP, et al. Conjoined twins twenty years' experience at a reference center in brazil. Clinics 2013;68(3):371-377. DOI: 10.6061/clinics/2013(03)oa14. 